\title{
NOTE ON TRANSLITERATION \\ AND TECHNICAL TERMS
}

There has been a recent tendency among historians of the Middle East to transliterate as precisely as possible, with full diacritical marks, all words originally written in the Arabic alphabet. This tendency will no doubt be welcomed by the specialist, but it must be deplored by the general reader for whom this book has been written. I have omitted all diacritics, in the belief that they distract the non-specialist and can be mentally supplied by the expert. I have transliterated each word in only one way, and have used standard English spellings where these exist, but beyond this I have not tried to be consistent.

A book about so technical a subject as the Royal Air Force must inevitably use some technical terms, but I have tried to keep these to the absolute minimum. Three, however, have been regularly employed.

Air policing means the use of aircraft to uphold the internal security of a state.

Air control occurred when the Air Ministry assumed responsibility for the defence of a particular region of the Empire. In the period discussed in this book, air control took place only in Palestine, Iraq, Transjordan, and the Aden Protectorate, although it was proposed for numerous other territories.

Air substitution occurred when aircraft replaced other forms of military force in imperial defence. The use of aircraft instead of ground troops to police a territory was one form of substitution, and the proposed use of bombers instead of heavy guns to defend Singapore would have been another.

My use of these terms corresponds to that employed, fairly consistently, by the Air Staff. 